\title{
Research on Crisis Warning Process of China- Myanmar Cooperative Hydropower Project
}

\author{
Xiaoli Zhu \\ College of Economics and Management \\ Yunnan Agricultural University \\ Kunming, China \\ lily7277@163.com \\ Hao Yin * \\ International Business School \\ Yunnan University of Finance and Economics
}

\author{
Kunming, China \\ yinhaoli@163.com \\ Peng Peng \\ International Business School \\ Yunnan University of Finance and Economics \\ Kunming, China \\ 1798511156@qq.com
}

\begin{abstract}
It is difficult to construct a hydropower station in Myanmar by transnational cooperation. Complicate social environment and erroneous management are the causes of crisis of hydropower project. So it is necessary to engage in crisis warning management for China-Myanmar cooperative project. Firstly, theory analysis about risk and crisis warning of transnational project were studied in literature review. Secondly, causes of crisis confronted by transnational hydropower project were analyzed from the view of social environment and internal management. Finally, the crisis warning process was discussed and the structure of warning process based on information centre was established. Using appropriate crisis warning process, the transnational project would reduce losses and bring less impact on society when the project encounter crisis.
\end{abstract}

Keywords—crisis warning; hydropower project; transnational cooperation

\section{INTRODUCTION}

As Myanmar enjoys good geographical conditions to develop hydropower projects, such as quite few reservoir inundation and good dam site landform and geographical conditions, countries with hydropower development capabilities strive for projects to co-develop hydropower with Myanmar.

Electricity power is much needed in Myanmar. However, due to the lack of funds and technology to construct hydropower stations, most of hydropower stations are constructed by cooperating with foreign companies and adopting BOT mode [1]. Myanmar has not yet formed a unified power grid system, since Myanmar national grid mainly transmits electricity to some fairly developed areas.

As a result, cooperation of power station construction has become an important part of economic \& trade cooperation between China and Myanmar. Outward transmission of electricity of Yunnan province of China to Myanmar will become the 4th economic channel for China to link Greater Mekong Subregion (GMS) following highway, railway and aviation" [2].

However, as neglect of risk management, short of corresponding crisis warning process in hydropower station construction, some hydropower projects of Chinese enterprises are confronted against crisis and cause massive loss in Myanmar.

Transnational projects with risk factors in uncertain environment are complicated projects. It can be seen that complicated projects own more factors to trigger crisis, and moreover, quite many stakeholders and considerable impacts are involved if crisis occurs.

As home and host countries are difference in politics, culture, economy and languages, so transnational hydropower projects face a large number of uncertain factors to trigger risks.

Once risks of transnational hydropower projects are transformed into hazards to the project, development teams of transnational hydropower projects are unable to take reasonable measures to reduce or make up for damages. The risk will further evolve to be crisis and cause more loss, even unsuccessful implementation and possible political issues to the countries of the project company and location. Hence transnational hydropower project is a large complicated project with lots of uncertain factors, and some risks are likely to cause severe crisis with impact on bilateral political diplomacy and society.

It is quite necessary to study ways to manage and control potential risks of hydropower projects, which may cause considerable impact on projects. However, it takes certain time for risk factors to transform into crisis, and relevant signs will emerge during the transformation. So enterprises engaged in transnational hydropower industry should get attention to risk events and relevant information before crisis events take place. Enterprises are hoped to formulate crisis warning process and control means, and work out reasonable plans to handle crisis.

Project information management is the center of crisis warning process in China-Myanmar cooperative hydropower

*Corresponding author 
stations. There are two main functions of the process. The first is to gather and analyze information related to the project, and promote the delivery of valid information related to the project crisis in component departments of the crisis warning process. The second is to strengthen linkage of departments involved in the crisis warning process, and prepare the project crisis warning plan more applicable for the project.

The structure of this paper includes five parts. These are introduction, literature review, analysis of the causes of crisis, constructing the process of crisis warning, and conclusion.

\section{LITERATURE REVIEW}

\section{A. Risk and Cristis}

Risks and crisis are all triggered by internal unreasonable factors and external interference factors. Risks that are not effectively managed in engineering projects and ignored will be evolved into crisis of engineering projects, and crisis is considered as the continued risks of engineering projects. Improperly managed risks are the roots of crisis [12].

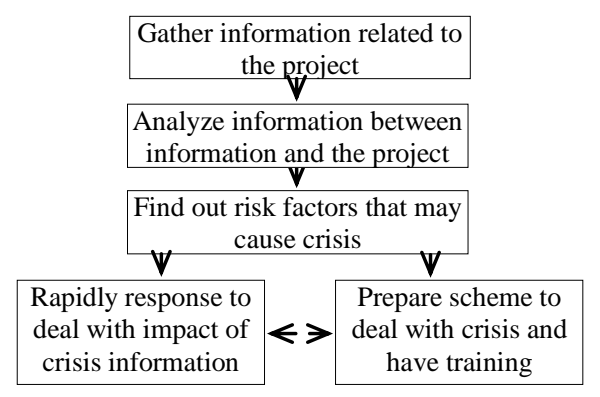

Fig. 1. Process of positive crisis precaution consciousness

Crisis and risks have the same characteristics, i.e. needing to resolve uncertain events that may result in loss within certain time [10]. However, compared with risks, crisis offers even shorter time; otherwise, it will give rise to more loss than general risks, and even irreparable loss.

Project management means management of risks and crisis. Crisis and risks affect the progress of projects. If risks and crisis are improperly managed, it will result in failure of projects [5]. Risks and crisis are roots of failure and loss of projects. Crisis will bring enormous pressure and mental burden on people. In order to handle it effectively, it is recommended to take it easy with a positive attitude [9].

When it comes to identifying factors that trigger crisis, it is found that transnational hydropower project companies always suppose the crisis has taken place, and then deduce factors that lead to crisis with the simulative scenario.

In the early period of crisis, it is supposed to capture signs, and establish the multi-level crisis response mechanism. Plan should be prepared according to identified risk factors in terms of preparation applicability, relations between plans and operability. Meanwhile, the plan should give consideration to linkage and coordination between different crisis plans and moreover, and linkage between departments to deal with and prevent crisis should be reinforced [8].

\section{B. Crisis Warning}

The direct tasks of crisis managers are to gathering, analyzing and spreading information. Managers need to take some key actions in first hours or days of crisis. It is a must to handle crisis in a timely, rapid and correct way. There are some signs when crisis takes place, and project management personnel need to grasp relevant signs [7].

There are certain signs when crisis takes place. Project managers need to gather and analyze relevant information, make effective decisions by using information related to the project, take effective measures to handle factors related to crisis in certain time, and eliminate crisis in emerging and developing phases, which is called crisis warning.

The effects of crisis warning may be classified into the following two types according to the attitude. These are positive crisis precaution consciousness and passive crisis precaution consciousness

Positive crisis precaution consciousness refers to initiatively recognizing crisis factors. Gathering information related to projects as much as possible, analyzing their influence on the project, finding out the relevance, and nipping crisis factors in the bud. In this way, crisis events lose conditions to evolve, and loss is avoided therefore [4]. The process of the positive precaution consciousness is as fig 1 .

Passive crisis precaution consciousness means adopting a passive attitude to identify risk factors, which may lead to crisis evens and damage, and passively gathering project related information. When the crisis event happens, the project team detects crisis related information and reports to the company, and the company organizes a special team to deal with crisis events, cuts down loss incurred, and wipes out negative impacts. The crisis warning process with the passive crisis precaution consciousness only resolves and eliminates the destruction and impact incurred from crisis in a passive way. The warning mode is a better late than never way after damage is caused. The process of the passive precaution consciousness is as fig 2 .

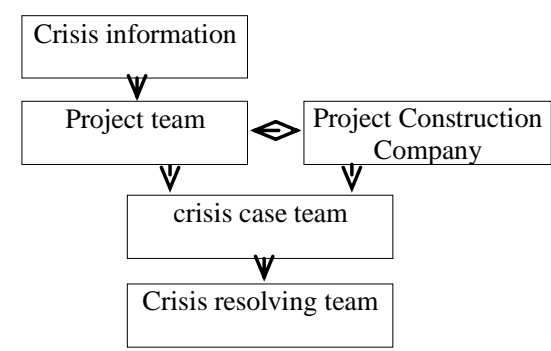

Fig. 2. Process of passive crisis precaution consciousness

\section{Crisis Information Warning and Control}

After grasping information related to the project, the project team needs to filtrate factors related to the crisis from a great amount of information, and filtrate if they are crisis factors. There are many ways to filtrate, for example, calculating the probability of crisis, or adopting the experts grading method to identify possible information, which may cause crisis grounded 
on expertise in relevant fields, or adopting scene reconstruction ways to simulate project running and crisis happening, as long as adequate project information is obtained [6]. The most effective way in the project crisis information identification stage is to employ professionals to gather and identify related information.

After information related to the project is identified, the project team may decide the most effective way to prevent and deal with crisis. It is very vital to prepare crisis handling plans, as it is used to prevent crisis, and deal with loss caused by the crisis, serving as the guide to instruct the project team to cope with crisis promptly when crisis occurs.

Communication is also the most effective way to prevent and deal with crisis. By effectively communicating with stakeholders, the project team is able to pass correct information related to the project among stakeholders.

\section{CAUSES OF CRISIS IN CHINA-MYANMAR COOPERATIVE HYDROPOWER PROJECT}

\section{A. Causes from Social Environment}

The crisis happened in the hydropower project in Myanmar is caused by the four causes from social environment.

First, the cause of political risk. Myanmar has relatively severe ethnic conflicts, and the central government and local government have conflicts, so certain risks exist for hydropower station projects in this country [11]. Myanmar is affected by so-called China threat to change its diplomatic policies [3].

Second, the cause of public opinion risk. When related information is not passed to those who pay attention to hydropower projects timely, the crisis of transnational hydropower projects will be caused by public opinion risks, and consequently stakeholders of the project, i.e. those who pay attention, guess and estimate the project construction unilaterally based on their knowledge to the project, and ultimately trigger potential crisis.

Third, the cause of environment protection conflicts risk. The conflicts with Myanmar in terms of environment protection concept is mainly because the transnational hydropower project construction party fails to communicate with Myanmar government about the design related to the dam construction, i.e. environment protection design, in a timely way, so the crisis in the transnational hydropower project construction was triggered.

The environmental issues caused by hydropower projects were exaggerated by NGOs within Myanmar, and even protest and demonstration activities were held. All of these exert negative influence on the project, such as construction suspension or delay, and trigger the construction crisis of hydropower projects to certain extent [13].

Fourth, the cause of ethnic conflict risk. China has become the largest constructor of hydropower projects in Myanmar, and Chinese hydropower enterprises rushing to Myanmar throws threats to economic sovereignty of Myanmar. Once nationalism emotions are involved, especially the third party forces involved in livelihood issues, the issue will become sensitive and complicated.

\section{B. Causes from Project Management}

Poor internal management may trigger the crisis of transnational hydropower projects. There are four causes of internal management.

First, cause of information management. Unsmooth information refers to the loss resulted from risk events due to no information acquired about the project, information shortage or late information.

Information is very important in handling and identifying crisis. If the decision-makers and project manager of the project construction company fail to obtain the information related to the project, their understanding and judgment about the risk factors and events will be affected, and they are quite likely to ignore risk factors. When meeting right conditions, risk factors will transform into risk events; if out of control, risk events will evolve into crisis events eventually, further causing more loss, and even resulting in failure of the project.

Project information is classified into two types according to the sources: firstly project information beyond the project progress, i.e. information related to the project caused by other potential stakeholders. The so-called potential stakeholders refer to individuals, organizations, etc. having no direct interest relations with transnational hydropower projects, and they do not reap profits from the project, but the transnational hydropower project construction will have negative impact on their interests. The other source of project information is from the project progress, for instance, raw materials on the site and construction parameters during actual construction progress, direct loss caused by natural disasters, etc.

Second, cause of team management. The crisis events were triggered when the rights and responsibilities of the project manager assigned by the hydropower project construction company were not clear and express, resulting in excessive power; or when the project manager lacks transnational hydropower project construction experience, and handles risk events improperly, resulting in risk events which causes larger scale loss.

As cultural quality of members on the project construction team is not uniform, the team members have inside conflicts or conflicts with native people due to improper management or lack of necessary trainings, which cause risk events. If the contradiction is not properly handled, it will evolve into the crisis event with considerable impact.

Third, cause of plan. Improper project implementation plan triggers risks when data related to the project is not gathered completely in the preliminary period, and transnational hydropower project manager and project construction company's decision-makers are too optimistic about the project prospect or have construction costs estimation errors. Moreover, the project manager and the project team amend the project planning during project implementation so as to send project progress feedback to the project construction company's decision-makers, so the risk events cannot be resolved and transformed into crisis events. 
Fourth, profit conflict. Conflicts of operating profits in transnational hydropower projects in Myanmar caused crisis. After transnational hydropower projects are put into operation, Burmese government thinks it gains less operating profits, so it is dissatisfied with transnational hydropower project construction. Chinese enterprises should define its rights and responsibilities in hydropower projects in Myanmar during all phases of the project, from construction, operation to transfer of ownership, and meanwhile hope Burmese government will complete laws and stipulations concerning foreign investment in Myanmar, ensure interests of foreign enterprises to the maximum extent, and protect interests of Burmese people at the same time [13].

The crisis factors that cause crisis events classified above are relevant. China-Myanmar hydropower projects are usually located in places with inconvenient transportation and communication, so information is not passed or gathered completely or smoothly, and this will easily lead to project planning errors, untimely communication between the company's management and the project implementation team. Therefore, the project team cannot amend the project planning in a timely way, and then risk factors will easily evolve into risk events that affect the project negatively. If the risk events evolve further and loss is expanded, crisis will take place.

\section{CRISIS WARNING PROCESS FOR CHINA-MYANMAR HYDROPOWER PROJECTS}

\section{A. Gathering Information}

The information about China-Myanmar cooperation hydropower projects is classified into two types: external information and internal information according to the source of project information.

The external information refers to the information generated by the external followers of the project (including the stakeholders of the project) on the relevant comments or speculation of the project, or the policies related to the project implementation.

The internal information of China-Myanmar cooperation hydropower project refers to the information about the implementation progress of the project, such as the progress, the cost, and quality of the project.

The ways to gather crisis external information are modern media and technical means, such as the media, network or political channels by embassies and offices established by the home country. In terms of internal crisis information gathering, project management software can be used to collect and send feedback information about the project.

\section{B. Set up Crisis Information Processing Department}

Transnational hydropower project construction companies should set up a department responsible to analyze and process information about risks and crisis. It is called project information management center (PIMC). The center should employ large number of project risk control professionals, or cooperate with other professional risk control companies, to conduct information management and handling on the condition that project information management center is granted with clear information processing power and relevant responsibilities.

The role of the center is to collect project information, professionally process and assess project information, find solutions, develop and modify the crisis handling plan suitable for the project implemented. The main role of the center is to timely handle the collected information that may cause the project crisis, and nip such information in the bud.

The center should also be equipped with a professional project information releasing system, and assign staffs to publish the project-related information regularly, so that stakeholders and the public will be provided with updated and correct information about the project. In case of crisis, project information management center should promptly communicate with the project team and representative offices or branch offices set up in the country where the project is located; and find ways to resolve the crisis or control the crisis, and guide the project team to handle the crisis according to the existing plan as well as the latest crisis handling ways; timely publish the crisis handling process and measures and other relevant information to the project liaisons and the media, thus eliminating jitters of project stakeholders and the project team to the greatest extent.

After the crisis is handled, project information management center should conduct a timely evaluation on the handling result of this crisis, investigate the causes, identify the persons directly responsible for the crisis, report to the project construction company, and find out what was improperly done in dealing with the crisis, so as to provide better risk handling measures for the next project.

\section{Communicate with External Crisis Followers}

Before the risk event causes losses, the representative office or branch set up in the country where projects is located should analyze the stakeholders of the project, and assist the project manager in communicating with the project stakeholders, so as to reduce risk factors resulted from lack of communication with stakeholders as much as possible.

It should be noted that the stakeholders of the project should be classified into two categories, namely, implicit stakeholders and explicit stakeholders.

Explicit stakeholders are the direct stakeholders, and their presence is usually obvious. Explicit stakeholders can benefit directly from the construction of transnational hydropower projects and their interests are directly related to the projects. They usually hold contracts concerning transnational hydropower projects, so they will focus on the process of transnational hydropower projects. In the country where the project is located, the office or branch manager and the project manager will communicate with the explicit stakeholders. The author believes that the progress of the project should be informed to the explicit stakeholders timely, in order to enhance their understanding and confidence of the project. Only in that way, if there is any problem, they will consider helping the project implementation team. When the project encounters difficulties, the project team can seek help from 
explicit stakeholders, who will lend a hand based on the profitability of the project. All in all, in addition to obtaining support from the project construction company, the project manager can also get resources and advice to solve the project crisis from other explicit stakeholders with common interests. Explicit stakeholders include the project material suppliers, the construction team employed, the final project owner, etc.

Implicit stakeholders mean that they are not directly related with the project by interests, but because of indirect impact on their related interests, they will also pay attention to the construction of transnational hydropower projects. When transnational hydropower projects are constructed, some areas will be submerged, which results in relocation of personnel, so residents living near the dam are originally unrelated to the projects, but in this way, they have direct interest relation with the project construction. In the country where the project is located, the branch office or branch manager and the project manager need to communicate with such implicit stakeholders. In addition to satisfying the conditions put forward by these stakeholders, it is also important to find out the consistent interest needs, which is a topic to communicate and exchange with implicit stakeholders. In the case of submerged areas of hydropower construction projects, the representative office or branch and project managers in the project country can have talks with residents living near the dam, persuade them that hydropower construction will facilitate their convenience of using electricity, and then reach consensus.

When a transnational hydropower project is constructed, the office or branch and project manager in the project country should communicate with the stakeholders of different types in the country, after analyzing information gathered during project construction.

One important principle for communicating with stakeholders of the project is to find the common interests of their most concern among all their concerns, and talk this with stakeholders, and thereby minimize the possibility of crisis and risk events.

\section{Resources Allocation to Deal with Crisis}

The project construction company should give the project manager enough authority to allocate resources of the company before the project kicks off, so as to address the crisis when necessary. Therefore, the project construction company should define rights and responsibilities of the project manager before the project gets started.

Before the transnational hydropower project has crisis, project information management center should assist the project responsible person to get resources allocation flow for crisis handling involved in the crisis handling plan, so that when crisis occurs, the project responsible person is able to obtain relevant resources to resolve crisis according to the flow.

Besides, the project manager is recommended to have frequent communication with the project's explicit stakeholders about the project related information, and attract the latter's attention to the prospect and progress of the project, so that when crisis occurs, the project manager is able to get more resources and assistance to resolve the crisis.

\section{E. Structure of Crisis Warning Process}

If project information management center is built, the crisis warning process may be rebuilt by focusing on project information management center. The details are as follows: before the project is implemented, the construction company authorizes and entrusts the project implementation team and project information management center to jointly prepare the project crisis handling plan, and the project implementation team is responsible for implementation.

When the project construction is under way, the project implementation team and the agency or branch set up by the project construction company should report the project related information to project information management center, and project information management center analyzes project related information, filtrate factors that may lead to crisis, finds out measures to prevent and resolve the crisis warning factors, reports to the head office, amends the project crisis handling plan, and sends feedback to the project implementation team. The author holds the opinion that in this way, crisis will be eliminated in the crisis factor phase and prevented from occurring. Authorized by the project construction company, the project implementation team and the agency or branch set up by the project construction company will carry out centralized management over project stakeholders and project related construction resources. Project information management center is responsible to release and analyze project related information, and provide guidance to the project team to handle the crisis. Fig 3 is structure of crisis warning process.

\section{F. Preparation and Drillings of Crisis Handling Plans}

Before the crisis handling plan is prepared, the project construction company needs to conduct risk assessment about the project to be implemented, find out risk factors that easily occur and cause giant loss, or possibly evolve into crisis and go out of control, and prepare the crisis handling plan according to national laws and stipulations concerning engineering construction and the company's internal crisis handling document. The project manager should carry out regular trainings for the team and disaster and loss prevention drillings as per the crisis handling plan.

After the project gets started, project information management center should analyze the project related information gathered, find out the most risk factors in the latest information, which possibly cause loss in project implementation, and those that may evolve into crisis, amend the crisis handling plan prepared before the project implementation when necessary, and submit the amended one to the project implementation team, which will control the project risks and crisis, and carry out disaster \& loss prevention trainings, emergency event handling drillings, etc. based on the updated plan. 


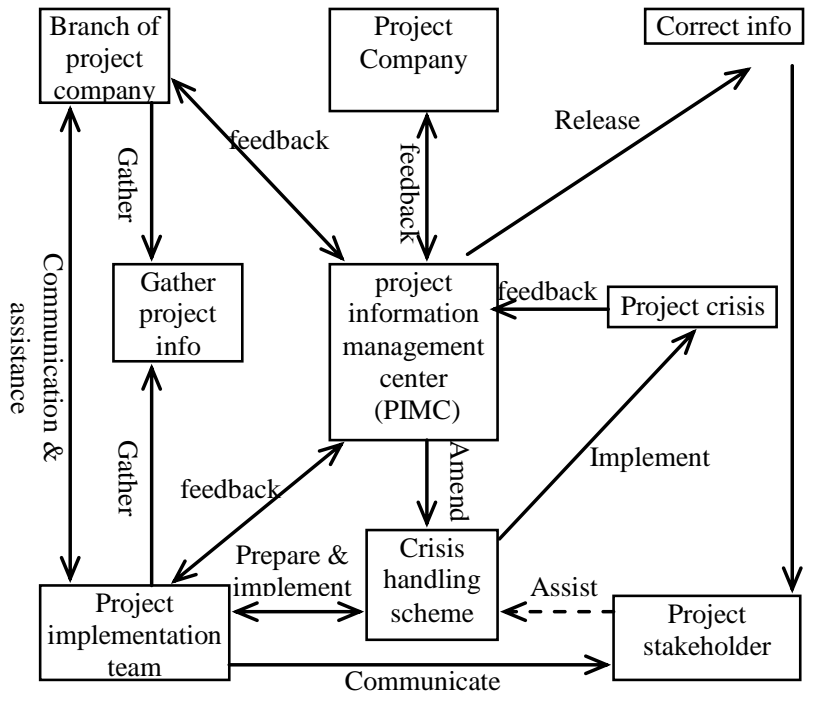

Fig. 3. Structure of crisis warning process

\section{CONCLUSION}

Based on review of literature, the causes of crisis were analyzed. There are environment factors and management factors. So a special information centre should be set up, which will gather project related information, analyze and identify crisis information based on professional knowledge, release correct related information to the project follower, and offer solutions based on signs of relevant project crisis. Base on the centre new crisis warning process are built.

Crisis of the project is gradually evolved from risk events out of control. Compared with risks, the crisis has the following characteristics: greater destruction, great psychological crisis to the people involved in the crisis event, and moreover, the crisis event requests the people involved in the crisis event to allocate limited resources to find a solution within an extremely short time. However, when the crisis just occurs, there are signs in front of the project implementer. If the project implementer is able to grasp and analyze these signs, the crisis can be warned and nipped in the bud. Therefore, the most effective way to resolve crisis is to correctly analyze information caused by the crisis, and pass correct information among those related to the project.

A new transnational hydropower project's crisis warning process are discussed. The process is able to promote correct information of crisis to be passed in the crisis warning process of China-Myanmar hydropower projects, and offer guide opinions in warning and handling crisis based on analysis of relevant crisis information.

\section{ACKNOWLEDGEMENT}

We would like to express our sincere gratitude to H.E. Gao Chongyun, for supporting us in investigation and collection data in Yunnan Machinery and Equipment Import and Export Corporation. We also want to thank the anonymous reviewers for their comments.

\section{REFERENCES}

[1] Jin Zhongyin, etc. "Myanmar Energy Industry Assessment" International Study Reference, 2013(03), pp.19-27.

[2] Li Yang.. "Analysis of Investment Environment and Mode of Hydropower Projects in the Union of Myanmar," China Development, 2011(S1), pp.34-39.

[3] Lin Jia, Qi Kai. "Burmese Diplomatic Policy Adjustment and ChinaMyanmar Energy Cooperation," Journal of International Relations, 2014(03), pp.52-61+154.

[4] Ma Jianxin. "Identify and Cope With Crisis in Construction Engineering Projects," Science \& Technology Information, 2012 (20), pp.447.

[5] Salewski,Wolfgang,L. V. Rosenstiel,and R. Zook. "The Management of Risk and Crises in Projects," Applied Psychology for Project Managers, 2015(12), pp.269-286.

[6] Wang Aimin. "Complicated Project Crisis Incentives and Grid-Based Crisis Management Mechanism," Technology Economics, 2013(1), PP.59-63.

[7] Wang Aimin, Jiang Wenchao. "Complicated Project Crisis Early Warning Grid System Design and Realization," Information Magazine, 2014(03), pp.155-160

[8] Xu Jiuping, Jiang Manli, Lu Yi. "Unconventional Emergency Management Mode of Large Hydropower Projects," Journal of Systems \& Management, 2013(5), pp.695-707+714.

[9] Xu Shouji, Ma Weizhen. "Study and Discussion on Crisis Management of Construction Engineering Projects," Journal of Lanzhou Jiaotong University, 2014(4), pp.27-30.

[10] Yin Hao, Fang Zijie. "Index System and Method of Sustainable Development Early Warning," Research of Agricultural Modernization, 2000(6), pp.332-336.

[11] Zhao Liting. "Kachin Development Network Organization and Myanmar Anti Myitsone Dam Movement," China Foreign Affairs University, Beijing(2015), pp.7-43.

[12] Zheng Yi. "Brief Discussion on Crisis Management of Construction Engineering Projects," Cooperative Economy \& Science, 2011(7), pp.53-54.

[13] Zhou Linhua, Liu Wenkun. "Opportunities and Risks in Myanmar Hydropower Cooperative Development," Yunnan Hydropower, 2016(5), pp.168-172. 